\title{
PERFORMANCE OF 119 BRAZILIAN CHILDREN ON STROOP PARADIGM - VICTORIA VERSION
}

\author{
Helenice Charchat-Fichman', Rosinda Martins Oliveira ${ }^{2}$
}

\begin{abstract}
Background: The Stroop paradigm evaluates susceptibility to interference and is sensitive to dysfunction in frontal lobes. Performance in the Stroop changes along the development. Despite its usefulness in research and clinical settings, there are few studies with Brazilian samples. Objective: This study investigates the performance and age effect on Stroop paradigm of Brazilian children. Method: A sample of 119 children, aged from 7 to 10 years, was submitted to the Victoria version of Stroop. Results: The pattern of results observed was similar to that observed in foreign studies with adults and children. Younger children were overall slower than older ones (positive correlation between age and naming time). Also, younger children showed more susceptible to interference than older ones (negative correlation between age and number of errors for the maximal interference condition). Conclusion: There was an age effect explained in terms of developmental changes in information processing velocity and attention selectivity.
\end{abstract}

KEY WORDS: attention, cognition, neuropsychology, child.

\begin{abstract}
Desempenho de 119 crianças brasileiras no paradigma Stroop - Versão Victoria
Resumo - Introdução: O paradigma Stroop avalia a susceptibilidade à interferência e é sensível a disfunção nos lobos frontais. O desempenho no Stroop muda durante o desenvolvimento. Apesar de sua utilidade na pesquisa e na clínica, existem poucos estudos brasileiros. Objetivo: Investigar o desempenho e efeito de idade de crianças brasileiras no Stroop. Método: A versão Victoria do Stroop foi aplicada em 119 crianças (7 a 10 anos). Resultados: $O$ padrão de resultados observado é comparável a estudos estrangeiros com adultos e crianças. Crianças mais jovens foram mais lentas do que as mais velhas (correlação positiva entre idade e tempo de nomeação). Os mais jovens apresentaram maior susceptibilidade à interferência, comparados aos mais velhos (correlação negativa entre idade e número de erros para a condição de interferência máxima). Conclusão: $O$ efeito de idade foi observado e discutido em termos de mudanças na velocidade de processamento da informação e na seletividade da atenção.
\end{abstract}

PALAVRAS-CHAVE: atenção, cognição, neuropsicologia, crianças.

The Stroop paradigm evaluates selective attention and cognitive flexibility, measuring the shifting ability to change demands and suppress an usual response in favor of an unusual one $e^{1,2}$. Speed of processing and conceptual abilities contribute to Stroop effect ${ }^{3,4}$. The Stroop is a neuropsychological task sensitive to dysfunction in frontal lobes, including neuropsychiatric disturbances as attention deficits hyperactivity disturbance (ADHD), anxiety and depression ${ }^{5-7}$. Stroop ${ }^{8}$ in 1935 originally developed this paradigm. His first version consisted of three white cards, each containing ten rows of five itens. There were four parts: (1) the subject read randomized color names printed in black; (2) the subject read the color names printed in color ink, ignoring the color of the print (the color print never corresponding to color names); (3) the subject named the colors of squares and (4) the subject received the card used in part 2 and had to name the color and ignore the verbal content. Normal people could read color words printed in color as fast as in black (part $2 \times$ part 1); but there was an increase in time to complete the task

\footnotetext{
'Doutorado, Departamento de Psicologia, Pontifícia Universidade Católica do Rio de Janeiro, Rio de Janeiro RJ, Brazil; '²Doutorado, Departamento de Psicologia, Universidade Estácio de Sá, Rio de Janeiro RJ, Brazil. Financial support: Conselho Nacional de Desenvolvimento Científico e Tecnológico - CNPq.
}

Received 16 June 2008, received in final form 19 January 2009. Accepted 16 April 2009.

Dra. Helenice Charchat-Fichman - Rua Visconde de Pirajá 550 / 616 - 22410-003 Rio de Janeiro RJ - Brasil. E-mail: hcharchat@uol.com.br 
when the person had to name the color of ink instead of reading the word (part $4 \times$ part 3 ). This difference in time was called "color-word interference effect".

Based on this first paradigm, proposed by Stroop, other versions have been developed ${ }^{9-11}$. Tests differ in the number of cards used, color dots or XXX, number of items in each card, number of color used, paper and pencil task or computerized ones. After Stroop version, the two most used in clinical practice and research are the Dodrill's and Victoria's formats.

Recently, some Stroop-like models were developed using computerized software. These models measure reaction time based on vocal response, using voice devices. These Stroop-like versions are similar to computer games and are very useful to evaluate children ${ }^{11-13}$. The Stroop-like computerized forms include blocks of incongruent, congruent and neutral trials, using colors, pictures or words of super-ordinate categories. The difference between incongruent and neutral condition is called interference and the difference between congruent and neutral condition is named facilitation. These cognitive constructs showed interesting results to explain the development of selective attention, inhibitory control and executive functions ${ }^{11-13}$.

Previous studies have shown that interference is larger among children compared to adults, in different versions of the Stroop and Stroop-like paradigms ${ }^{11,13,14-21}$. Others, in a smaller number, have not observed an age effect on interference measures, in these paradigms ${ }^{12,22}$. These findings have been discussed in terms of different measures of interference being employed, strong dependency of the tasks on other competences that the children may not yet have acquired (as reading, for younger children, for example), as well as age span of the sample studied ${ }^{12,13}$.

Typically, for the classic color Stroop some minimal interference is present early in the beginning of reading acquisition and it raises as reading level increases. Afterwards, during adolescence and adult life, interference decreases, to raise again after 60 years of age $\mathrm{e}^{6}$. For Stroop-like tasks not requiring reading, children in early childhood (more or less until 5 years of age) show the highest interference effect. This effect declines rapidly during childhood (roughly between 5 and 10 years of age), and attain adult levels by the end of childhood and beginning of adolescence ${ }^{11,13}$.

Among the hypothesis examined in the literature ${ }^{11,23}$, there are strong evidence that these results might be understood in terms of inhibitory control having a developmental trajectory during childhood. Inihibitory control is a cognitive process that allows subjects to delay or to prevent a pre-potent response, making it possible to modify well-learned responses when alternative behavior is demanded ${ }^{13,24,25}$. The action of inihibitory control contributes to attentional selectivity, especially for controlled attentional processes, mediated by the central executive.

In the last 5 years, some studies in Brazil began to employ the Stroop paradigm to assess atentional selectivity in adults ${ }^{26,27}$ and children ${ }^{28,29}$ with different pathologies as, for example, ADHD and head trauma injury. Also, in one study, normative data were collected for pre-adolescents between 12 and 14 years of age $\mathrm{e}^{30}$. All these studies employed the Victoria version, except for the Cabacco et $\mathrm{al}^{28}$, and some of them used computerized versions.

Taking into account the uselfuness of this paradigm to assess attentional selectivity and inihibitory control and the reduced number of studies on it with Brazilian samples, this study describes performance and age effect on Stroop paradigm of 119 Brazilian children from Rio de Janeiro, age range from 7 to 10 years.

\section{METHOD}

Subjects

Participated in this study 119 subjects, 59 boys and 60 girls, aged from 7 to 10 years, students of private schools in Rio de Janeiro (Table 1). The subjects were from socioeconomic classes $C$ and $D$, as estimated from parent professions and incoming

Table 1. Demographic characteristics.

\begin{tabular}{lccccc}
\hline & 7 years & 8 years & 9 years & 10 years & $\mathrm{P}$ \\
\hline $\mathrm{N}$ & 37 & 28 & 34 & 20 & \\
Sex & & & & & \\
$\quad$ Female & 20 & 10 & 19 & 11 & $>0.05^{\mathrm{a}}$ \\
$\quad$ Male & 17 & 18 & 15 & 9 & \\
Education & & 0 & 0 & 0 & \\
$1^{\text {st }}$ grade & 4 & 13 & 0 & 0 & \\
$2^{\text {nd }}$ grade & 23 & 10 & 10 & 1 & $<0.05^{\text {b }}$ \\
$3^{\text {rd }}$ grade & 1 & 0 & 22 & 5 & \\
$4^{\text {th }}$ grade & 0 & 0 & 2 & 14 & \\
$5^{\text {th }}$ grade & 0 & 0 & & & \\
\hline
\end{tabular}

${ }^{a}$ chi-square comparing sex frequencies between different ages; ${ }^{b}$ chi-square comparing education grade frequencies between different ages. 
Table 2. Mean and standard deviation for the conditions color, word and incongruent, for naming time and number of errors.

\begin{tabular}{lccc}
\hline & Color & Word & Incongruent \\
\hline Naming time & & & \\
$\quad$ Mean & 23.28 & 31.15 & 44.01 \\
Standard deviation & 7.61 & 9.82 & 14.6 \\
Number of errors & & & \\
$\quad$ Mean & 0.14 & 0.043 & 0.89 \\
Standard deviation & 0.52 & 0.20 & 1.62 \\
\hline
\end{tabular}

reported. All children in the age band of interest were included as subjects, except those with diagnosed neurological or neuropsychiatric disturbances. These informations were collected from a questionnaire filled in by parents. For all subjects the informed consent was obtained from parents and the study was approved of institutional ethics comitee.

\section{Procedure}

The subjects were tested individually in a separate room inside the schools. The material used was paper, pencil and a tape recorded to register the subject's responses.

All subjects were submitted to Stroop-Victoria version ${ }^{1,10}$. It consists of three cards, each containing six rows of four items. In part 1 (color) the subject must name, as quickly as possible, the color of 24 rectangles printed in blue, green, red or yellow. In part 2 (word), the rectangles are replaced by common words printed in color and the subject must name the color, ignoring their verbal content. Part 3 (incongruent) is similar to parts 1 and 2, but the color stimuli are color names printed in an incongruent color that is never the same designated by the word printed (e.g. to blue printed in red, the subject must produce the word "red").

For each of the three conditions, the number of errors was recorded as well as the time to complete the naming of all stimuli (with a stopwatch). Also, for each subject it was calculated the interference score as the quotient between the time score for the incongruent (part 3) and color (part 1) conditions.

\section{Statistical analysis}

Initially, the internal consistency of the all set of results was tested using Pearson's correlation. The effect of condition was tested with one-way ANOVA for naming time (LSD analysis) and number of errors. The differences between each two conditions were submitted to $t$ tests. Finally, the age effect was tested with an ANOVA and with Pearson's analysis of correlation between age in months and the different scores measured.

\section{RESULTS}

There was a significant correlation between the three conditions studied for naming time $(-0.38<\mathrm{r}$ values $<$ $-0.32, p<0.0001)$. The correlation between conditions for the number of errors was not significant. Table 2 shows the results for the three conditions studied, in terms of naming time and number of errors (mean and standard deviation).

The oneway ANOVA showed a significant condition effect $(F(2)=185.43, p<0.01)$. The subjects were slower to name the colors in the incongruent condition, both compared to the color condition $(t(116)=19.23, p<0.01)$ and the word condition $(t(116)=16.12, p<0.01)$. Naming time was also longer in the word than in the color condition $(t$ (116) $=11.44, p<0.01$ ).

Regarding the number of errors, the ANOVA showed a significant condition effect $(F(2)=15.95, p<0.01)$. The number of errors was greater in the incongruent condition, compared to the word condition $(t(116)=5.61, p<0.01)$ and to the color condition ( $t(116)=5.01, p<0.01$ ). There was a tendency to the number of errors to be larger in the word than in the color condition $(t(116)=1.88, p=0.063)$.

Age in years (7, 8, 9 and 10 years) and condition (color, word and Incongruent) effects were tested with ANOVA for each of the three scores studied. It was observed significant differences for age groups regarding naming time. The results in terms of mean, standard deviation, as well as $\mathrm{F}$ and $\mathrm{p}$ values are presented in Table 3.

Concerning naming time, a LSD analysis has shown that, taking the three conditions together, 7 years olds were slower than $8(p=0.03), 9(p<0.01)$ and $10(p<0.01)$ years olds. In the conditions word and incongruent, 7 years old were slower than $9(p=0.01 ; p=0.03)$ and 10 years olds $(p<0.01 ; p=0.01)$; and the 8 years olds were slower than 10 years olds $(p=0.02, p=0.04)$.

Concerning number of errors, the 7 years olds made more errors both in Word and in the Incongruent conditions ( $p=0.03$ e $p=0.02$ ), compared to 9 years olds. For the word condition, 7 years olds also presented greater number of erros than 8 years olds $(p=0.03)$.

Aiming a better understanding of the age factor, it was performed, for each condition, a correlation analysis between age in months and naming time, number of errors and Interference scores. The transformation of the age categories (discrete variable) in age in months (more continuous variable) has the advantage to allow the study of changes along shorter time intervals. 
Table 3. Age groups analysis: means, standard deviation and ANOVA results.

\begin{tabular}{|c|c|c|c|c|c|}
\hline \multirow[t]{2}{*}{ Stroop/Age } & 7 years & 8 years & 9 years & 10 years & ANOVA \\
\hline & Mean $\pm S D$ & Mean $\pm S D$ & Mean \pm SD & Mean \pm SD & F. $p$ \\
\hline \multicolumn{6}{|l|}{ Naming time } \\
\hline Color & $27.00 \pm 9.79$ & $23.04 \pm 5.08$ & $20.48 \pm 6.30$ & $21.35 \pm 5.05$ & 5.42. $p<0.01$ \\
\hline Word & $35.7 \pm 11.61$ & $32.44 \pm 8.27$ & $28.18 \pm 8.05$ & $25.9 \pm 6.64$ & 6.53. $p<0.01$ \\
\hline Incongruent & $50.35 \pm 17.34$ & $45.37 \pm 15.03$ & $40.24 \pm 10.16$ & $36.7 \pm 9.36$ & 5.35. $p<0.01$ \\
\hline Interference & $1.96 \pm 0.58$ & $1.97 \pm 0.52$ & $2.03 \pm 0.46$ & $1.95 \pm 0.52$ & 1.17. $p=0.32$ \\
\hline \multicolumn{6}{|c|}{ Number of errors } \\
\hline Color & $0.16 \pm 0.50$ & $0.15 \pm 0.77$ & $0.15 \pm 0.44$ & $0.05 \pm 0.22$ & $0.22 . p=0.88$ \\
\hline Word & $0.11 \pm 0.32$ & $0.00 \pm 0.00$ & $0.00 \pm 0.00$ & $0.05 \pm 0.22$ & 2.24. $p=0.09$ \\
\hline Incongruent & $1.32 \pm 2.09$ & $1.00 \pm 1.75$ & $0.42 \pm 1.06$ & $0.70 \pm 0.20$ & 1.97. $p=0.12$ \\
\hline
\end{tabular}

It was found a significative negative Pearson correlation between age in months and naming time for each of the three conditions: color $(r=-0.32, p<0.01)$, word $(r=$ $-0.38, p<0.01)$ and Incongruent $(r=-0.37, p<0.01)$. Also, age in months was correlated with number of errors in the Incongruent condition $(r=-0.19, p=0.04)$. These results indicate that the younger the children, longer are the naming time and the number of errors. The number of errors was not correlated with age in months for the conditions color and word, neither was it the interference score.

\section{DISCUSSION}

In terms of naming times the data showed internal consistency; there was a significant correlation between individual scores for the three conditions. Concerning the number of errors, the correlation between conditions was not significant, probably because these errors were rare among the subjects. A very small number of errors is a common result for healthy subjects in this paradigm ${ }^{1,12}$.

Naming times and number of errors on the Stroop task systematically increased from the color through the word and finally to the incongruent condition. This is the classical pattern found on the Stroop tasks both with adults, adolescents ${ }^{1,6}$ and children ${ }^{15}$. These results are explained in terms of the difficulty of inhibiting a pre-potent over-learned response (reading), in favor of naming the color the word is printed in, a much less authomatic response $\mathrm{e}^{1,6}$.

There was an age effect for naming time: older children were faster than younger ones, on each of the three conditions studied, and this effect was more pronounced when the 7 years olds were compared to the other age groups ( 8,9 and 10 years olds). These results are in line with previous studies that found age effects on time scores for the Stroop ${ }^{12,15,16}$ and are explained in terms of the overall increase of information processing velocity along the normal human development ${ }^{15,16}$.

There was a similar effect on the susceptibility to interference that decreased in a more marked way between ages 7 and 8 . Also, there was a significant age effect on number of errors exclusively for the incongruent condition: the younger the child, more errors she makes when interference is maximized. Nevertheless, there was not an age effect on the interference score or an interaction between condition and age for naming time. However, in the Stroop the magnitude of interference is estimated both by longer times and/or greater number of errors in the incongruent compared to neutral or minimal interference conditions'.

These results are in line with the evidence that interference may have a development trajectory during childhood. For word Stroop tasks, similar to the classical paradigm, the differences are observed only when 7-8 years children are compared with children older than 9 years or adolescents. If the sample only includes children older than 9 years, the age effect is not observed ${ }^{12,15,31,32}$. These findings support the hypotheses that reading becomes automatic after 9 years of age and, because of that, interference scores increase and reach adult level ${ }^{12,15,3,3,32}$. In addition, when Stroop-like tasks without words were used, changes in susceptibility to interference were observed from 3 years of age, becoming more marked between 5 and 8 years. Thus, the age effect on interference is probably due to attention development and not only automatic reading response ${ }^{13,18,19,33}$.

\section{REFERENCES}

1. Spreen O, Strauss E. A compendium of neuropsychological tests. New York: Oxford University Press, 1998:326-340.

2. Lezak MD. Neuropsychological assessment ( $3^{\text {rd }}$ ed.). New York: Oxford University Press, 1995:438-445.

3. Graf P, Uttl B, Tuokko H. Color-and-picture-word-Stroop tests: performance changes in old age. J Clin Exper Neuropsychol 1995;17:390-415.

4. Sherman EMS, Strauss E, Spellacy F, Hunter M. Construct validity of WAIS-R factors: Neuropsychological test correlates in adults referred for possible head injury. Psych Assess 1995;7:440-444. 
5. Raskin A,Friedman AS, DiMascio A. Cognitive and performance deficits in depression. Psych Bull 1982;18:196-202.

6. McLeod CM. Half a center of research on the Stroop effect: an integrative review. Psych Bull 1991;109:163-203.

7. Hanes KR, Andrews DG, Smith DG, Pantelis C. A brief assessment of executive control dysfunction: discriminant validity and homogeneity of planning, set shift and fluency measures. Arch Clin Neuropsyc 1996;11:185-191.

8. Stroop JP. Studies of interference in serial verbal reactions. J Exper Psychol 1935;18:643-662.

9. Dodrill CB. A neuropsychological battery for epilepsy. Epilepsia 1978;19: 611-623.

10. Regard M. Cognitive rigidity and flexibility: a neuropsychological study. Dissertation, University of Victoria, 1981.

11. Bub DN, Masson ME, Lalonde CE. Cognitive control in children: Stroop interference and suppression of word reading. Psychol Sci 2006;17:351-357.

12. Wright BC, Wanley A. Adults' versus children's performance on the Stroop task: interference and facilitation. Br J Psychol 2003;94:475-485.

13. Wright I, Waterman M, Prescott $\mathrm{H}$ et al. A new Stroop-like measure of inhibitory function development: typical developmental trends. J Child Psychol Psychiatry 2003;44:561-575.

14. Carter CS, Nintun M, Cohen JD. Interference and facilitation effects during selective attention: an H2150 PET study of Stroop task performance. Neuroimage 1995;2:264-272.

15. Comalli PEJr, Wapner S, Werner H. Interference effects of Stroop color-word test in childhood, adulthood and ageing. J Gen Psychol 1962;100:47-53.

16. Guttentag RE, Haith MM. Automatic processing as a function of age and reading ability. Child Dev 1978;49:707-716.

17. Vurpillot E, Ball WA. The concept of identity and children`s selective attention. In Hale GA, Lewis M (Eds), Attention and cognitive development. New York: Plenum, 1979:23-24.

18. Gestardt CL, Hong Y, Diamond A. The relationship between cognition and action: performance of children 3,5 to 7 years old on a Stroop like day-night test. Cognition 1994;53:129-153.

19. Welsh MC, Pennington BF, Groisser DB. A normative-developmental study of executive function: a window on prefrontal function in children. Dev Neuropsychol 1991;7:131-149.

20. Balaban MT, Snidman N, Kagan J. Attention, emotion and reactivity in infancy and early childhood. In Lang PJ, Simons RE
(Eds), Attention and orienting: sensory and motivational processes. Hillsdale, NJ: Erlbaum, 1997:369-391.

21. Girelli L, Lucangeli D, Butterworth B. The development of automaticity in accessing number magnitude. J Exp Child Psychol 2000;76:104-122.

22. Jerger $S$, Stout G, Kent M et al. Auditory Stroop effects in children with hearing impairment. J Speech Hear Res 1993;36: 1083-1096.

23. Yeung N, Botivinick MM, Cohen JD. The neural basis for error detection: Conflict monitoring and the error-related negativity. Psychol Rev 2004;111:931-959.

24. Barkley RA. Behavioral inihibition, sustained attention and executive functions: constructing a unifying theory of ADHD. Psychol Bull 1997:121:65-94.

25. Luria AR. Higher cortical functions in man. New York: Basic Books, 1966.

26. Mattos P, Saboya E, Araújo C. Seqüela comportamental póstraumatismo craniano: o homem que perdeu o charme. Arq Neuropsiquiatr 2002;60:319-323.

27. Machado DCD, Bastos VHV, Silva PAP, et al. Gênero e níveis d atenção: Diferenças sexuais encefálicas e níveis de atenção em homens e mulheres. Fitness Perf J 2005;4:232-235.

28. Cabaco AS, Colas IC, Hage $S$ et al. Selectividade atencional e predisposição emocional face a estímulos do comportamento alimentar: dimensões transculturais. Anal Psicol 2002;4: 625-633.

29. Assef ECS, Capovilla ASG, Capovilla FC. Computerized Stroop test to assess selective attention in children with attention deficit hyperactivity disorder. Span J Psychol 2007;10: 33-40.

30. Duncan MT. Obtenção de dados normativos para desempenho no teste de Stroop num grupo de estudantes do ensino fundamental em Niterói. J Bras Psiquiatr 2006;55:42-48.

31. Merril EC, Sperber RD, McCauley C. Differences in semantic enconding as a function of reading comprehension skill. Mem Cognit 1981;9:618-624.

32. Visser M, Das-Smaal E, Kwakman H. Impulsivity and negative priming: evidence for diminished cognitive inhibition in impulsive children. Brit J Psychol 1996;87:131-140.

33. Diamond A, Taylor, C. Development of an aspect of executive control: development abilities to remember what I said and to do as I say not as I do. Dev Psychobiol 1996;29:15-334. 